\title{
Facebook: Perils, Perceptions And Precautions
}

Claire Reeves La Roche, Longwood University, USA

Mary A. Flanigan, Longwood University, USA

St. Clair Reeves La Roche, Tulane University, USA

\begin{abstract}
Facebook is one of the fastest growing applications of the Internet. Social networking via Facebook provides a popular way for students and others to connect with a wide audience and expand their circle of friends. Facebook account holders have been denied admission to universities, not hired for jobs, lost scholarships, been disciplined by college administrators and arrested for online postings and exercising what they consider to be their right of free speech. A survey of 118 undergraduate students and 45 employers was conducted in an effort to determine their Facebook habits and perceptions about proper postings. Recent cases involving disciplinary action, restrictions on Facebook use and the First Amendment are discussed. Suggestions are made for safer Facebook protocol.
\end{abstract}

\section{INTRODUCTION}

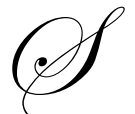

ocial networking is one of the fastest growing uses of the Web. Many students assume that the First Amendment protects their right to free speech and by extension protects them from punishment for posting their social life online. This assumption is false and many students have learned the hard way that making their private life public may have detrimental consequences. Many employers and prospective employers now search the Internet for information about current and potential employees. In 2007, Proofpoint Inc. surveyed 308 companies with more than 1,000 employees and found that $9.1 \%$ had terminated employees within the past year for what they considered to be inappropriate Internet postings (Proofpoint, Inc., 2007).

One of the most popular tools for social networking is Facebook. "Facebook gives people the power to share and makes the world more open and connected. Millions of people use Facebook everyday to keep up with friends, upload an unlimited number of photos, share links and videos, and learn more about the people they meet." (Facebook.com)

Facebook pages are often created and maintained without considering the potential audience or appropriateness of the postings. In many cases students reveal information about themselves that they would not want family members, college administrators or prospective employers to see. This paper describes the history and common uses of Facebook and provides recent examples of disciplinary incidences related to online postings. In an effort to determine student and employer perceptions and online social networking habits, 118 undergraduate students and 45 employers were surveyed and the results are discussed. Finally, suggestions are made for the safer use of social networking sites.

\section{FACEBOOK PHENOMENON: HISTORY AND POPULARITY}

In the March 2008 Social Networking Survey of 118 undergraduate students, $96 \%$ indicated that they have a Facebook page. Facebook, a tool initially meant to connect students and members of a college community to one another, was founded February 4, 2004 by Mark Zuckerberg, a sophomore at Harvard (Levy, 2007). Originally, The Facebook.com was created exclusively for use by the Harvard community. Within two weeks of the appearance of The Facebook.com, approximately 4,300 students, faculty and alumni at Harvard had joined the service (Levy, 2007). What may be even more impressive is that by the end of March, 2004, students at Yale, Columbia, and 
Stanford were using Facebook (Levy, 2007) and Facebook was rapidly becoming the social networking tool of choice of college students. Facebook extended its network to high schools in 2005 and to corporations in 2006 (Levy, 2007). By 2007, anyone was allowed to join Facebook, resulting in a surge in the number of members with an estimated growth rate of $3 \%$ per week (Levy, 2007). The Facebook website currently claims 175 million active users (who have returned to the site in the last 30 days.) (Facebook.com) The site's popularity may be explained in part by the number and ease of use of its functions and applications.

According to Zuckerberg, Facebook is designed to target people who are part of one's "social graph" -- a map of real-life connections (Levy, 2007). One feature of Facebook is the mini-feed, an application that displays updates on members in a user's social network. For instance, once Facebook is aware of your social graph, other members may upload and automatically send updates, including photos, to all of the users in your social network. Users also form groups to share common interests, support a cause or a candidate, or to collaborate on projects with people outside their company or institution.

Facebook has multiple other features. The "Wall" acts as a bulletin board on every user's profile page. Friends may post messages here. "Pokes", a communication not unlike teasing, allows a user to send a "poke" to another user along with a notification that they have been poked. "Status" informs users' friends of where they are and what they are doing. "News Feed" contains updates on friends, including profile changes. "Facebook Notes" and "Comet-based" are similar to blogs and instant messaging. Recently Facebook launched "Gifts" allowing users to send virtual gifts to others with a personal message. This application, however, is not free. Each gift costs $\$ 1$. (Wikipedia)

One of the most popular applications of Facebook is the ability to post an unlimited number of photos. Users catalog photos into albums. The privacy setting may vary with the different albums: viewed only by "friends" or open for viewing by all Facebook users. Additionally, photos may be "tagged" or labeled naming those in the photo. If a photo is "tagged" a notification is sent to the person informing them that they have been tagged and providing them with a link to the photo. The "tagged" person may remove the tag from the photo but is not able to remove the photo. (Facebook.com) Who may view the photo will depend on the privacy setting on the poster's site and the members of their group and so on. Facebook accounts may be "open" or restricted to "friends". An "open" page can be seen by "friends" and anyone in their network. A network consists of anyone with the same university or school e-mail address. As can readily be seen, privacy and the unintended dissemination of information and photographs can be a major problem.

\section{UNEXPECTED CONSEQUENCES}

Facebook is an astonishingly popular tool that chronicles daily social interactions. With the ubiquitous camera-phone and small digital cameras, subjects are often not even aware they have been photographed until the images appear online. One typical Facebook user commented that "I can't go to a sorority formal or football game without photos from the event winding up on Facebook, uploaded by me or a friend." (Soller, 2007). Michael Phelps, Olympic gold medal swimmer, recently experienced this very costly lesson. Thus, Facebook postings are by their very nature a public activity. Photos and online postings that are intended to be "private" may very well end up being viewed by the public, particularly with the "mini-feed" application. It is worth remembering that once a posting is made online, even if it is later removed, it may have been saved by another viewer.

Even though a Facebook page may be set to "private", law enforcement and governmental entities have the capability to access all Facebook accounts. Applicants for jobs in the Obama administration were required to fill out an extensive questionnaire including the following requests:

"(13) Electronic communications: If you have ever sent an electronic communication, including but not limited to an email, text message or instant message, that could suggest a conflict of interest or be a possible source of embarrassment to you, your family, or the President-elect if it were made public, please describe. 
(14) Diaries: If you keep or have ever kept a diary that contains anything that could suggest a conflict of interest or be a possible source of embarrassment to you, your family, or the President-elect if it were made public, please describe.” (Calmes)

A high profile example of Facebook postings causing embarrassment occurred when photos of Miss New Jersey, Amy Palumbo, surfaced in an alleged extortion scheme aimed at having Palumbo resign her title. According to her mother, the security on Amy's Facebook page was "private" and thus she assumed that the pictures would remain private (Parry, 2007).

As stated above, Facebook accounts may be "open" or restricted to "friends". An "open" page can be seen by anyone with the same university or school e-mail address. This means that professors and administrators at their institution are able to access students' profiles. Figure 1 below shows that of the students surveyed, $43 \%$ said that their Facebook page was "open." Of those students who have attempted to restrict access to their Facebook page by only allowing Facebook "friends" to view it, one in five (21\%) admitted that they will add anyone to their profile who indicates a desire to be their "friend".

Figure 1. Percentage of Students with Open versus Closed Accounts

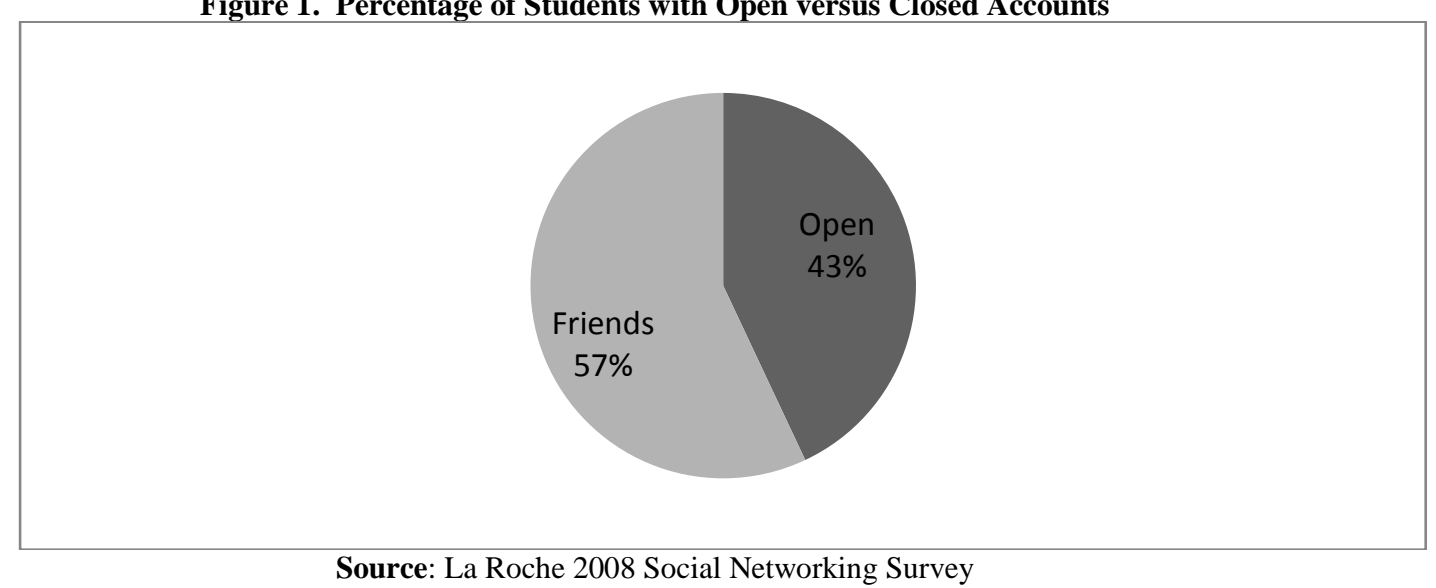

Facebook users have a tendency to make their private lives public, either voluntarily or through the actions of others. Although a Facebook user may not have direct control over photos that are posted by others, the presence of photos with their names attached may be "tagged" or tracked. Figure 2 shows that approximately one third of Facebook users surveyed, consistently "tag" their photos.

Figure 2. Percentage of Students "Tagging" Photos

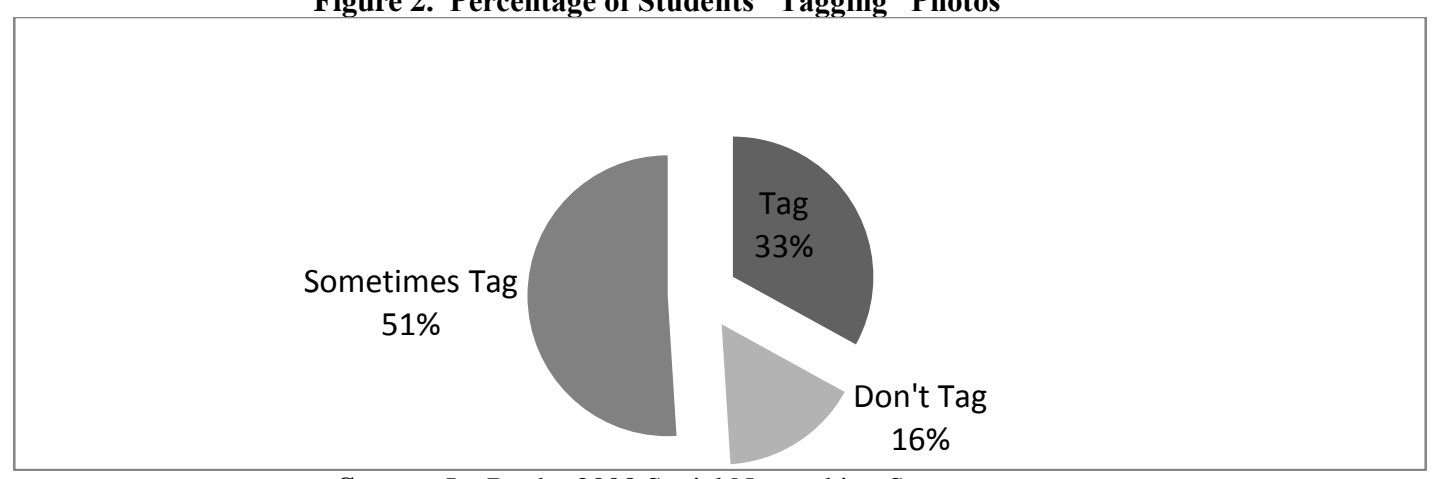

Source: La Roche 2008 Social Networking Survey 
The Social Networking Survey revealed that many of the students surveyed are aware of the adverse consequences associated with Facebook activity. The chart below indicates that $25 \%$ of the students surveyed were aware that college administrators have used information on Facebook to deny a student admission, $43 \%$ were aware of instances in which college scholarships have been withdrawn, $51 \%$ were aware of disciplinary matters linked to Facebook postings, and 59\% were aware of employers terminating or disciplining employees based on information posted on Facebook or other blog sites. Given the survey results illustrated by Figure 3, it is difficult to understand how college students assume that Facebook only interests people in their social circle.

Figure 3. Student Awareness of Consequences

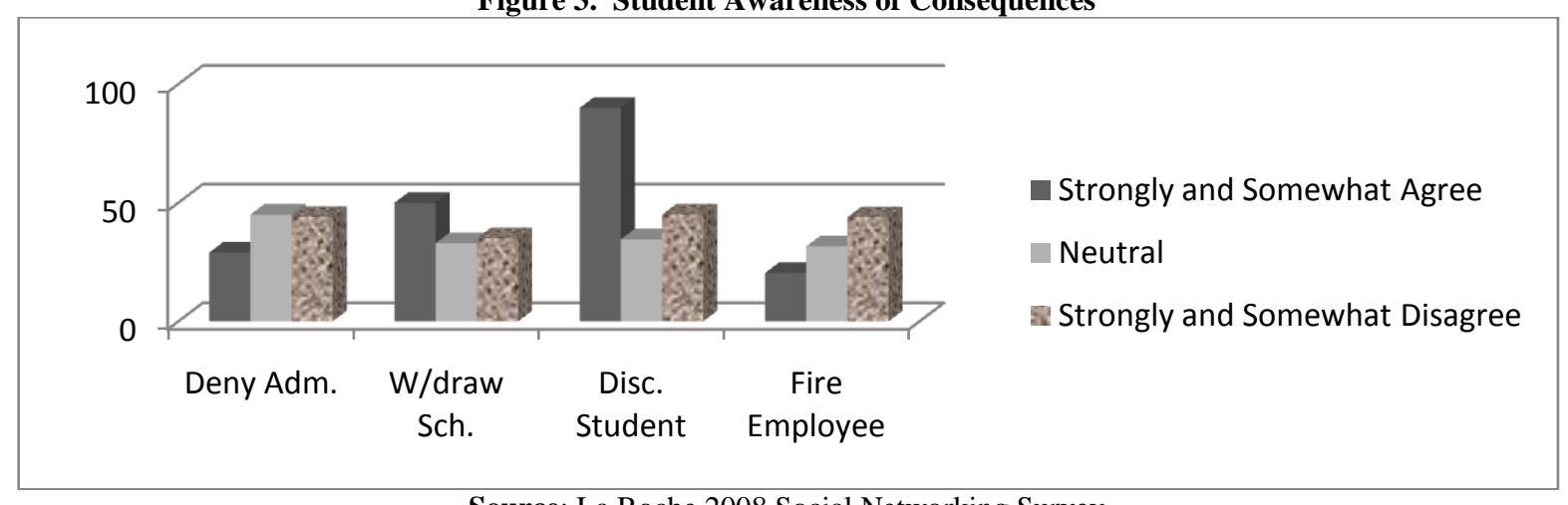

Source: La Roche 2008 Social Networking Survey

Although the extent to which colleges and universities use Facebook in admissions decisions is unclear, there is at least one documented case in which an applicant was denied admission to college based on disparaging remarks posted on LiveJournal (Veradi, 2006). "A Kaplan survey of 320 admissions officers from the nation's top colleges and universities revealed that one out of ten admissions officers has visited an applicant's social networking web site as a part of the admissions decision-making process." (Kaplan, 2008) According to the Kaplan survey, "38 percent report that applicants' social networking sites have generally had a negative impact on their admissions evaluation." (Kaplan, 2008) In another recent survey of 493 universities conducted by the University of Massachusetts-Dartmouth, "21\% of higher-learning institutions admitted to finding Facebook "very helpful" to their administration in marketing and recruiting strategies." (Efrus, 2008). Dr. Nora Gainum Barnes, Ph.D., the researcher who conducted the Massachusetts-Dartmouth study states, “...if schools do use Facebook as a resource, they would not overtly admit it." (Efrus, 2008)

To date, there are numerous documented cases linking Facebook to student disciplinary proceedings, loss of scholarships for student athletes, and even expulsion from universities. In an early incident, a Fisher College student was expelled for posting the following comments about a campus police officer on Facebook: "either we get a petition going (we need at least 500 signatures) or we try to set him up. He's got to do something wrong, in either case, he's gotta foul up at some point...anyone willing to get arrested?" (Schweitzer, 2005) In some cases, campus police have been known to use the site to monitor student behavior and crack down on underage drinking and sometimes criminal behavior (Maternowski, 2006). In one instance, campus police at Penn State University used Facebook to find students who had charged the football field after their team defeated Ohio State University. The police tracked down the students by spotting a Facebook group called "I Rushed the Field after the OSU Game (And Lived!)" (Maternowski, 2006). This group contained tagged photos linked to the students' respective pages. The pictures were then used as evidence. Penn State's campus police also reported that they usually use Facebook to investigate harassment claims.

Like many other university students, student athletes have been known to be avid Facebook users. In one case, two LSU swimmers, Eddie Kenney and Matt Coenen were dismissed from the team for posting disparaging comments about their coaches (Brady and Libit, 2006). In another case, two Colorado athletes, football player Clint O'Neal and his girlfriend, Jackie Zeigle, were given a ticket for harassing a Hispanic cross country runner. The 
incident led to the suspension of O'Neal from the Champs Sports Bowl and Zeigle's resignation from the cross country team (Brady and Libit, 2006).

What have been viewed to be "inappropriate" Facebook postings have also resulted in the expulsion of some students from their university. At John Brown University, openly gay student, Michael Guinn, was expelled for "violating the community covenant" (Tobias, 2006). Despite being warned by the university not to advertise his sexuality, Guinn did not remove photos of himself dressed in drag from his Facebook page prior to admission. His expulsion occurred shortly after one student complained about the photos. Although not directly stated, university officials claim that Guinn's sexuality was an implicit violation of student behavior as it pertains to the covenant.

In yet another case, Valdosta State University student T. Hayden Barnes was "administratively withdrawn" in part because Barnes was extremely vocal in his opposition to the university's plan to construct two new parking garages that would cost $\$ 30$ million of students' mandatory fees (Guess, 2008). Barnes posted fliers, mailed letters to administrators, and sent mass e-mails to students. Apparently, the tipping point was a collage of photos posted on Facebook "showing President Zaccari, a bulldozer aside the parking garage, and the phrases "No Blood for Oil" and S.A.V.E - Zaccari Memorial Parking Garage"." (Glazowski, 2008)

Employers and prospective employers also look at social network postings. "(C)ollege career counselors and other experts say recruiters are starting to look up applicants on sites like Facebook, MySpace, Xanga, and Friendster..." (Finder, 2006). In a 2006 survey conducted by the National Association of Colleges and Employers, almost $27 \%$ of prospective employers Google employees and search social networking sites and 35\% indicated that they may implement this practice (Nicita, 2007). ExecuNet, an executive job-search company, conducted a survey in 2005 that indicated that $75 \%$ of recruiters used Web research to screen applicants (Verardi, 2006). According to a 2007 Proofpoint survey, approximately $10 \%$ of the companies surveyed have terminated an employee and $20 \%$ have disciplined an employee for weblog or message board postings (Proofpoint, 2007).

\section{EMPLOYER VERSUS STUDENT PERCEPTIONS OF PROPER POSTINGS}

Increasingly, users of social networking sites are facing unintended consequences for their public commentary and photos posted online. The authors surveyed 118 students and 45 employers. The employers were asked their opinions of the appropriateness of ten Facebook images including two virtual applications, seven photos and one sketch that had been posted by college students. The students were asked how they felt the employers would react to the same images.

Facebook includes many virtual applications such as "Happy Hour" and "Naughty Gifts". For instance, the Happy Hour application allows users to send virtual cocktails. When employers and students were surveyed about the appropriateness of the above mentioned applications, their perceptions were remarkably similar. In fact, $39.6 \%$ of employers either somewhat or strongly agreed that the virtual "happy hour" was offensive and 35\% of the students surveyed acknowledged that a college administrator or prospective employer would find this application offensive. Similarly, $77.7 \%$ of employers either somewhat or strongly agreed that the "naughty gifts" application was inappropriate and $64 \%$ of college students thought that college administrators and employers would be offended.

Figure 4 illustrates the divergence between the students' perception of what employers believe and employers' opinions of the appropriate use of photos and images on Facebook. Employers who either "somewhat" or "strongly" agreed that an image was offensive are represented by the dark/ taller bars and the students' perception of whether employers would be offended by the same images is denoted by the light/shorter bars. ${ }^{1}$

\footnotetext{
${ }^{1}$ Image 1 was a photo of three co-eds wearing short cocktail dresses with the back of a shirtless male in the foreground. Image 2 was two males feeding what appears to be an alcoholic beverage to a dog. Image 3 was two co-eds posing with "handles" of alcohol. Image 4 was a cartoon drawing entitled "Boob girl (You) last night". Image 5 was a young man wearing a "hoodie" making what could be construed as "gang signs" with his hands. Image 6 was a young man with his face in a pitcher of beer. Image 7 was two girls at the beach blowing a kiss - one of the girls had JUICY on bikini bottom. In image 8, one girl was licking the shoulder of another girl.
} 
Figure 4. Employers' Opinions and Students' Perception of Employers' Opinions

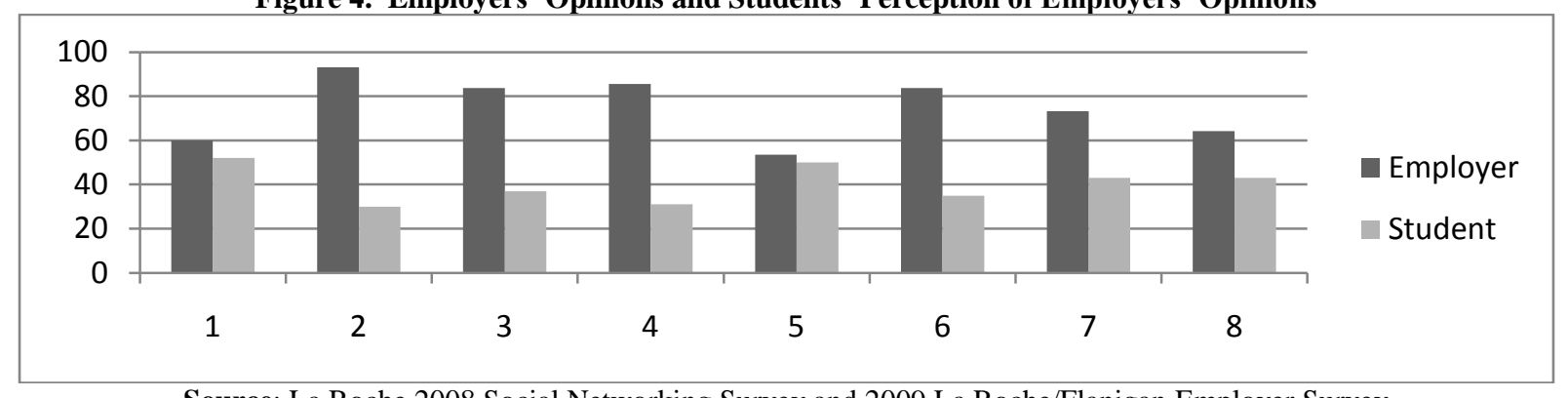

Source: La Roche 2008 Social Networking Survey and 2009 La Roche/Flanigan Employer Survey

\section{RESTRICTING USE OF FACEBOOK}

Many schools view their athletes as ambassadors and when athletes post photos or comments chronicling illegal and/or embarrassing behavior, college administrators become upset. Such events have caused universities like Florida State and Kentucky to monitor what their student athletes post on their pages, while others, such as Loyola University in Chicago, have decided to ban student athletes from Facebook (Brady and Libit, 2006).

Can colleges legally restrict their students' use of Facebook? In other words, when students create Facebook pages that are not defamatory, does the First Amendment protect their right of free speech? The First Amendment protects citizens from government censorship and provides that "Congress shall make no law..." that abrogates our right of free speech. It restricts government control of speech and thus, private schools clearly have more power than state supported schools to restrict the use of Facebook. According to Sheldon Steinbach, general counsel for the American Council on Education, "The state can't impose what one might consider unconstitutional restrictions" (Kornblum and Marklein, 2006) on students enrolled at state supported colleges and universities. (Kornblum and Marklein, 2006) Students at private universities, on the other hand, “... are voluntarily agreeing to abide by the rules and regulations in the student handbook. (Kornblum and Marklein, 2006)". According to Kermit L Hall, a First Amendment expert and the president of the University of Albany, it is probably acceptable for colleges to restrict athletes use of Facebook (Brady and Libit, 2007). Hall bases his assessment on the fact that "(s)tudents who join those teams submit to a certain degree of regulation that doesn't follow the rest of the student population... There are team rules on curfews and other things and if one of those rules is you can't be on Facebook - or, if you are, that you present yourself in a way that shows the values of the university - I think schools can do it." (Brady and Libit, 2007)

Even though students at state supported schools have a First Amendment right to use Facebook, students have a tendency to forget that the right to free speech does not protect them from the unwanted consequences of their expressions. Of the 118 students surveyed, $41 \%$ admitted that they have something on their Facebook page that a college administrator or employer would find offensive. An additional question as yet to be addressed by the courts is the power of the public university to restrict activities when they provide the network and/or equipment used to create or maintain the Facebook page.

\section{CONCLUSION}

Students have a tendency to post photos and personal information without giving much thought to the potential consequences of making this personal information public. Facebook pages may be seen by unintended viewers and may conflict with the expectations of present or future employers, coaches, and college administrators. Whenever a Facebook posting is made, it is safe to assume that essentially anyone may access that information.

Perhaps, the best solution to the Facebook dilemma is to delete one's page altogether. However, should you decide to keep your page, the following tips may help protect your reputation:

- $\quad$ Periodically Google yourself and see how you are viewed by the online world. 
- Be selective in choosing your "friends" -- employers have been known to look at your contacts.

- Use privacy settings to limit access to your Facebook page.

- Monitor your online presence by "tagging" photos so you can track content that includes your image.

- Immediately request that offensive photos be removed.

- $\quad$ Avoid revealing embarrassing, or offensive details about yourself.

- Never post a photo of yourself engaged in an illegal activity or one involving alcohol. As a rule of thumb, if you don't want your parents to see it, then don't post it.

- $\quad$ Do not associate with a fringe group that espouses radical views.

- $\quad$ Avoid posting inflammatory or controversial remarks.

Extreme caution should be taken before posting any personal information online. Even after entries have been removed, it is possible that they have been saved on a computer. The use of Facebook is not absolutely protected by the First Amendment right to freedom of speech. Users of social networking sites may be held accountable for their speech and students may be subject to additional restrictions. It is important to understand that the First Amendment does not insulate a speaker from responsibility for comments posted online. What one person considers funny today, may have adverse consequences and cause embarrassment in the future.

\section{REFERENCES}

1. Brady, Erik and Libit, Daniel (2007), Alarms sound over Facebook time, USA Today, http://www.usatoday.com/sports/college/other/2006-03-08-athletes-websites_x.htm

2. Calmes, Jackie (2008), For a Washington Job, Be Prepared to Tell All, The New York Times, http://www.nytimes.com/2008/11/13/us/politics/13apply.html?_r=2\&hp\&oref=slogin (accessed $1 / 28 / 2009)$.

3. Efrus, Zoe. (2008), Some Colleges use Facebook in making admission decisions, The Hawk Talk Online, http://www.the hawktalk.com/getArticle.php?id=208

4. Facebook Homepage, http://Facebook.com (Accessed 2/14/2009).

5. Finder, Alan (2006), Guess who's looking at your Web page: college-admissions officials and employers are starting to check out candidates on Web sites like Facebook and MySpace, New York Times Upfront, http://www.the freelibrary.com//print/PrintArticle.aspx?id=153239525.

6. $\quad$ Glazowski, Paul (2008), Facebook User's Photo Led to Expulsion from University http://mashable.com/2008/01/13/facebook-users-photo-led-to-expulsion-from-university/

7. Guess, Andy (2008), Maybe He Shouldn't have Spoken His Mind, Inside Higher Ed, http://www.insidehighered.com/news/2008/01/11/valdosta

8. Kaplan CAO Survey (2008), At top schools, one in ten college admissions officers visits applicants' social networking sites, http://www.kaplan.com/aboutKaplan/pressreleases/archive/2008/KaplanCAOSurveyResults.htm (accessed 2/13/2009).

9. Kornblum, Janet and Marklein, Mary Beth, What you say online could haunt you, USA Today, http://usatoday.printthis.clickability.com/pt/cpt?action=cpt\&title=USATODAY.com+-+Wh...

10. Levy, Stephen (2007), Facebook grows up, Newsweek, http://www.newsweek.com/id/32261

11. Maternowski, Kate, (2006), Campus police use Facebook, The Badger Herald, http://badgerherald.com/news/2006/01/25/campus_police use fa.php

12. Nicita, Lisa (2007), Don't get fired before you're hired, Arizona Republic, http://www.azcentral.com/business/articles/0728resumegaffes0728.html

13. Parry, Wayne (2007). 'Private' Online Photos Really Aren't, http://www.foxnews.com/wires/2007Jul12/0,4670,BeautyQueenBlackmailPrivacy,00.html

14. Proofpoint, Inc. (2007) "Outbound email and Content Security in Today's Enterprise" www.proofpoint.com

15. Schweitzer, Sarah (2005), When students open up - a little too much, The Boston Globe, http://www.boston.com/news/education/higher/articles/2005/09/26/when_students_open_u... (Accessed $1 / 28 / 2009)$.

16. Soller, Kurt. (2007), Why I love it... Newsweek, http://www.newsweek.com/id/32261 
17. Tobias, Josh (2006), The other Brown University: JBU expels lone openly gay student, Brown Daily Herald, http://media.www.browndailyherald.com/media/storage/paper472/news/2006/02/15/CampusWatch/TheOther.Brown.University.Jbu.Expels.Lone.Openly.Gay.Student-1614021.shtml

18. Verardi, Nicole, (2006), MySpace in College Admission, National Association for College Admission Counseling, http://www.nacacnet.org/MemberPortal/News/StepsNewsletter/myspace_students.htm

19. Wikipedia, Facebook features, http://en.wikipedia.org/wiki/Facebook_features (Accessed 2/15, 2009).

\section{NOTES}

